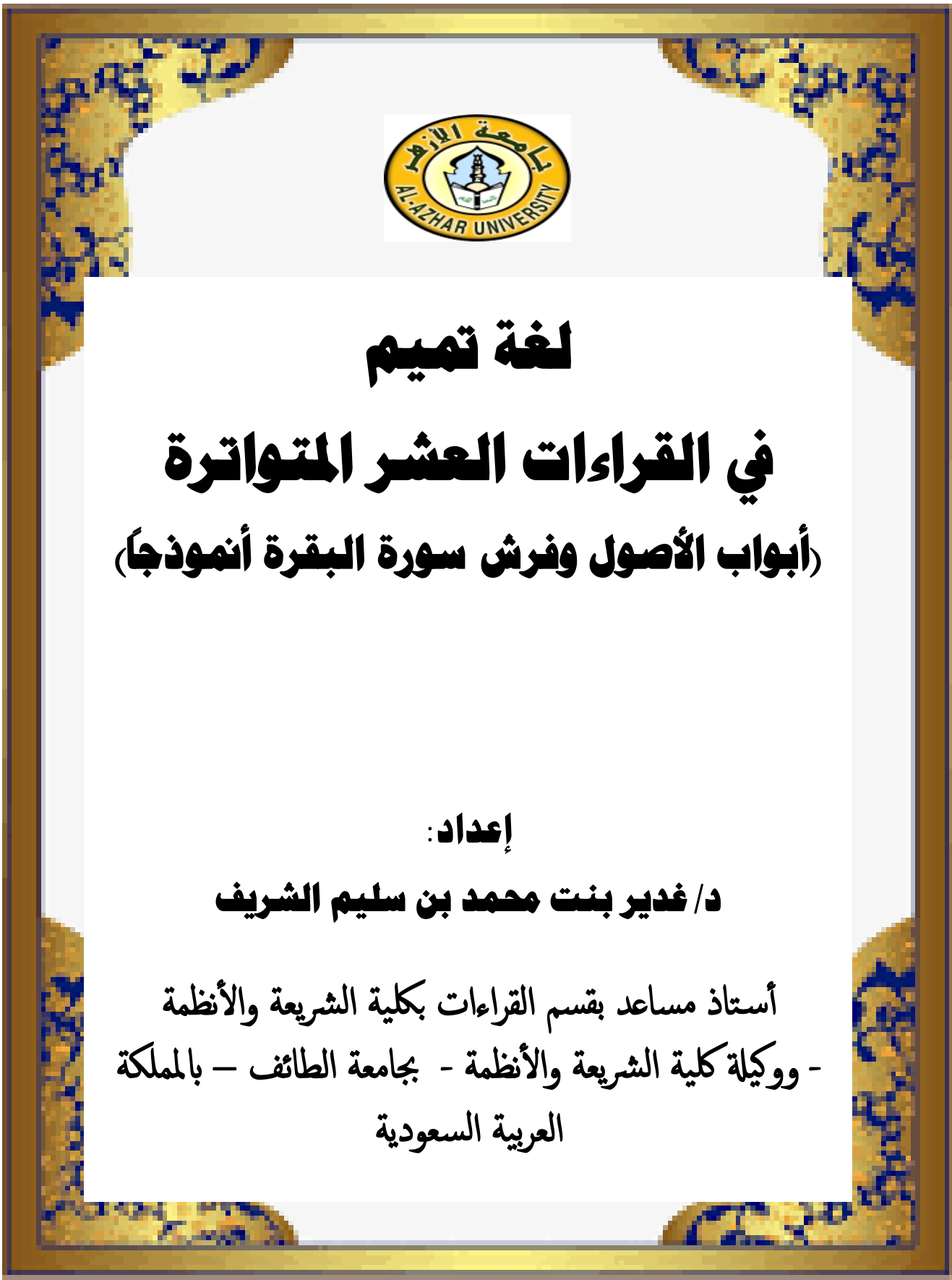
مجلة كلية أصول الدين والدعوة بأسيوط / العدد السابع والثلاثون 9 ـ بام ـ الجزء الثاني 


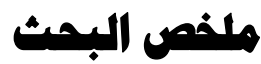

الحمد لله وحده، والصلاة والسلام على من لا نبي بعده ، ويعد:

فهذا بحث بعنوان : لغة تميم في القراعات العشر المتواترة .

بينتُ فيه : أهمية هذا الموضوع؛ وذلك لتعلقه بالقرآن الكريم وقراءاته المتواترة، وييان دور القراءات القرآنية في حفظ لغات العرب ولهجاتها. وذكرثُ أهداف هذا البحث، ومنها: الكشف عن بعض وجوه مواققة القراعة لبعض اللهجات التي لم تعد مشهورة؛ دفعاً لتوهم عدم مواققة القراعة للعربية الذي مهي هو ركن في قبولها.

وقد جاءت هذه الدراسة في: مقدمة، وتمهيد، ومبحثين، وخاتمة . بينتُ في المقدمة: أهمية هذا الموضوع، وأهدافه، والدراسات السابقة، والخطة التي اتبعتها في تقسيمه، والمنهجية التي سلكتها في جمع مادته وكتابته، حيث اقتصرثُ على أبواب الأصول، وسورة البقرة كنموذج للاراسة. وذكرتُ في التمهيد : أثهر القبائل في اللهجات العربية، كما عرّفتُ بقبيلة تمبيم وتحدثُ في المبحث الأول عن: القراعات القرآنية واللهجات، وجعله في

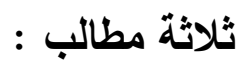

- المطلب الأول: تعريف اللغة واللهجة، والفرق بينهما. - المطلب الثاني: مصادر اللهجات العربية. 
- المطلب الثالث : أهمية القراعات القرآنية في دراسة اللهجات العربية. وذكرثُ في المبحث الثاني: لغة تميم في القراءات العشر المتواترة، وجعته في مطلبين:

- المطلب الأول: القراءات التي يرجع الاختلاف فيها إلى الجانب الصوتي. - المطلب الثاني: القراءات التي يرجع الاختلاف فيها إلى الجانب الصرفي. وأما الخاتمة : فقد ضمنتها أبرز النتائج، ومنها : ( )- تعدد مصادر اللهجات العربية . r) - تعدّ القراءات القرآنية أهمّ وآصل مصادر اللهجات العربية؛ وذلك لوثاقتها، وتتوعها، وعلم أصحابها بالعربية، وعدالتهم. 


\section{(ABSTRACT) $)$}

Praise be to Allah alone. Peace and Blessing be upon the none prophet after him.

This research is entitled: Tamim Language in The Tenth Frequent Readings readings (the doors of assets and brushes of Surat Al-Baqara as a model). Prepared by Dr. / Ghadeer bint Mohammed bin Salim al-Sharif

In which I pointed out: the importance of this subject, in which related to the Holy Quran and its frequent readings, and to declare the role of the Quranic readings in preserving Arabic languages and its dialects.

I mentioned the objectives of this research, which are:

- To disclosure some faces of reading approval for some of the dialects that

are no longer famous; to conceive the lack of Arabic reading approval, that is the pillar in its acceptance 
This study came in: introduction, preface, two researches, and a conclusion.

In the introduction I mentioned, the importance of this subject, its objectives, previous studies, the plan followed in its division, and the methodology used in collecting the subject and writing of the material, Where it was limited to assets chapters, and Surah Al-Baqarah as a model for the study

I, mentioned in the preface: The most famous tribes in Arabia dialects, as known as Tamim tribe.

I spoke in the first research about: The Quranic readings and dialects, and made it in three requirements :

- The First requirement: definition of language, dialect, and the difference

between them.

- The Second requirement: sources of Arabic dialects.

- The Third requirement: The importance of the Quranic readings in Arabic dialects study. 
I, mentioned in the second research: Tamim's language in the tenth frequent readings, and made it in two requirements:

-The First requirement: The readings that are due to the difference to the audio side.

-The Second requirement: The readings that are due to the difference to the morphological side. The conclusion: I included it by the most important results, such as:

1) Multiple sources of Arabic dialects.

r) The Quranic readings are the most important sources of Arabic dialects, for its documented, diversity, their knowledge in Arabic, and their justice. Keywords: Language - Readings - Frequency Doors - Assets - Brushes.

Email.Al-shareefanghadeer@hotmail.com 


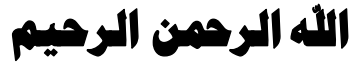 \\ الإقدمة}

الحمد الله وكفى، والصلاة وإلسلام على نبيه المصطفى، وعلى آله وأصحابه، ومن سار على نهجهم إلى يوم الدين ، ويعد ..

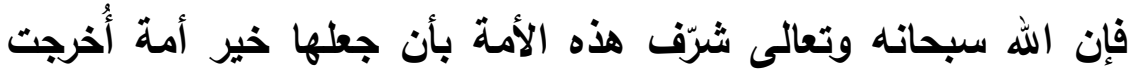

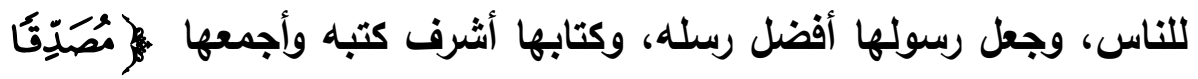

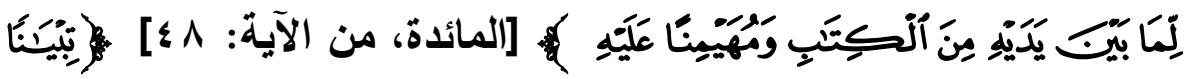

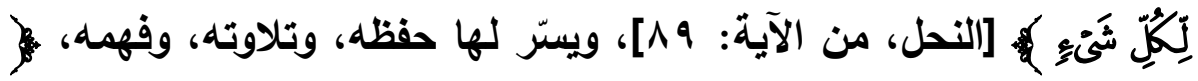

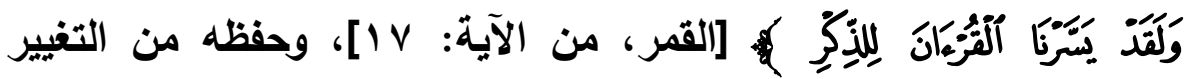

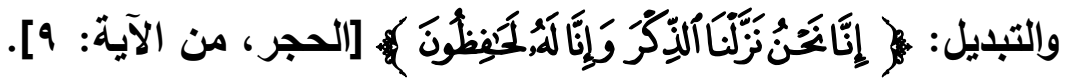
ومن مظاهر هذا الحفظ وذاك التيسير: القراءات القرآنية، فإنها تيسير من الله لهذه الأمة، كما هو ظاهر حديث إنزال القرآن على سبعة أحرف، وفي حفظ تلك الأحرف والأوجه التي أُنزل عليها القرآن دلالة ظاهرة على حفظ القرآن الكريم من التغيير والتبديل، ومظهر من مظاهر التيسير على الأمة الإسلامية عامة، والأمة العربية التي شوفهت بالقرآن الكريم خاصة، فإنها كانت قبائل كثيرة، وكان بينها اختلاف في اللهجات، ونبرات الأصوات، وطريقة الأداء، وشهرة بعض الألفاظ في بعض المدلولات، ورغم أن العروية كانت تجمعها، ويوحد بينها اللسان العربي العام، إلا أنه لو نزل القرآن على حرف واحد لثثق ذلك عليها، بل قد يكون بعضهم لا يقدر على ذلك، ولا بالتعليم والعلاج، لا 


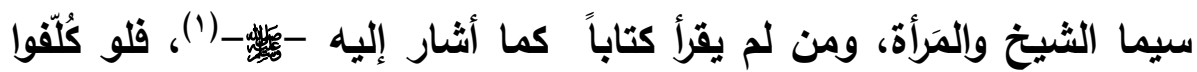
العدول عن لغتهم، والِانتقال عن ألبِنتهم، لكان من التكليف بما لا يستطاع (ץ).

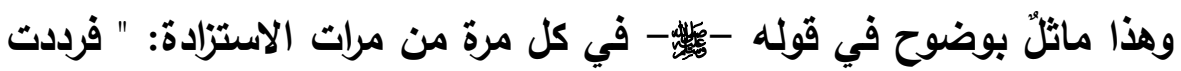

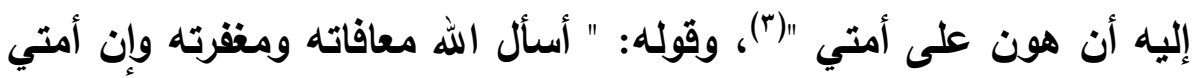
لا تطيق ذلك "(\{)، ومن أنه -صلى الله عليه وسلم- لقي جبريل فقال: "يا جبريل إني أرسلت إلى أمة أمية، فيهم الرجل والمرأة والغلام والجارية والثيخ

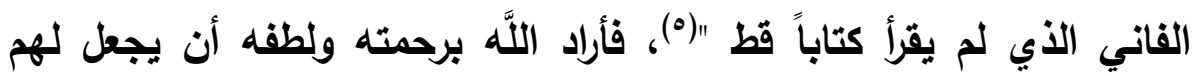
متسعاً في اللغات، ومتصرقًا في الحركات، كتيسيره عليهم في الاين("). وإذا كان العلماء والباحثون قد اختلفوا في تعيين الأحرف السبعة: فإنهم لم يختلفوا في أن تعدد اللغات داخل فيها: كالهمز، والتسهيل، واللقتح، والإمالة، وغيرها من أوجه القراءات التي تعود إلى اختلاف اللهجات، وإن كان الأصل في ذلك كله : الأخذ عن رسول الله

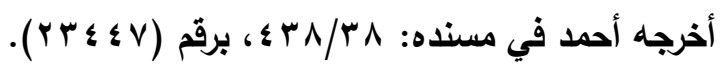

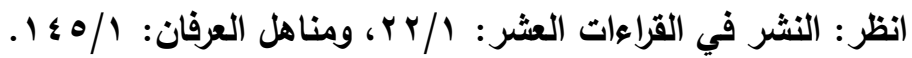

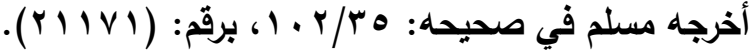

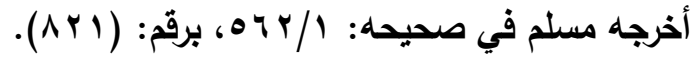

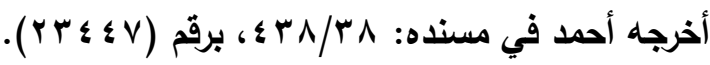

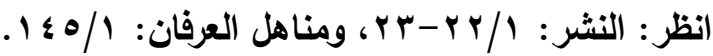


ويكون القرآن الكريم -بقراء|ته- خير حافظ للّفات واللّهجات، ويكون الاعتناء بالقراءات شكرًا لنعمة الله في تيسيرها على الأمة بإنزال القرآن على سبعة أحرف، ومن هنا جاء اختياري لهذا الموضوع.

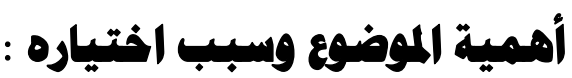
ا ـ تعلقه بالقرآن الكريم وقراعاته المتواترة. r . . دور القراعات القرآنية في حفظ لغات العرب ولهجاتها. r. كون القراعات القرآنية أهمّ وآصل مصادر اللهجات العربية. ع. أهمية لهجة تميم؛ كونها أهم روافد اللغة العربية الفصحى. أهد|ف البشث :

()-الإسهام في بيان أثز القراعات القرآنية في حفظ اللهجات العربية (الفصيحة . (1)

r)-بيان بعض وجوه الحكمة من نزول القرآن على سبعة أحرف؛ تخفيفاً على الأمة في تلاوته بما تعوّد بعضهم من أوجه النطق . r)-الكثف عن بعض وجوه موافقة القراعة لبعض اللهجات التي لم تعد التم مشهورة؛ دفعاً لتوهم عدم موافقة القراعة للعربية الذي هو ركن في قبولها.

\section{الدراسات السابقة:}

بعد البحث والتقصي لم أجد من تعرض للغة تميم في القراعات العثر المتواترة بالبحث والدراسة، وقد وجدت بعض الدراسات التي تحدثت عن اللهجات والقراعات القرآنية، وهي: ا - (اللهجات العربية في القراعات القرآنية الشاذة): لعبدالجبار عبدالله العبيدي، وهو بحث منشور في مجلة: جامعة الأنبار للغات والآداب، 
العدد (1) 9 . . برم ، تعرض فيه الباحث إلى بعض القراءات الثاذة

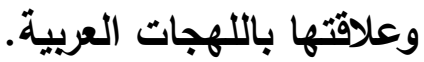

r- ( اللهجات العربية في القراءات القرآنية ) : للاكتور: عبده علي الهات الراجدي")، تحثث فيه المؤلف عن: حدود شبه الجزيرة العربية، وأقسامها، والثواقع اللغوي قبل الإسلام ، وأسباب نشأة اللهجات،

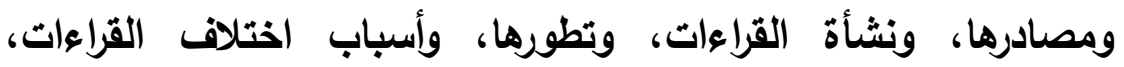
وأنواعها، ودراسة لغوية في اللهجات.

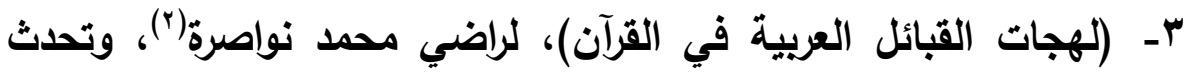
المؤلف فيه عن: نثأة اللهجات وتاريخها، وأصول اللهجات في القراءات القرآنية، وظاهرة الوقف في اللهجات العربية. ع- (لهجة تميم وأثرها في العربية الموحدة)، لغالب فاضل(־)، تعرض فيه المؤلف لاراسة خصائص لهجة تميم، وصلتها باللهجات الأخرى.

\section{فطة البمث ومنهبه:}

قت بتقسيم هذا البحث إلى: مقدمة، وتمهيد، ومبحثين، وخاتمة. أولاً: المقدهة: بيّتُ فيها: أهمية الموضوع وأسباب اختياره، واللاراسات

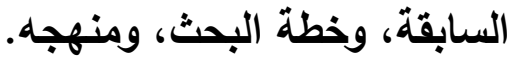

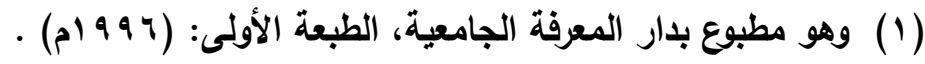

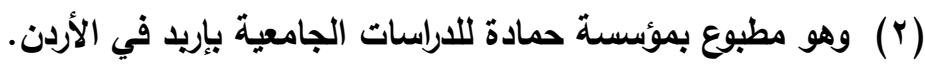

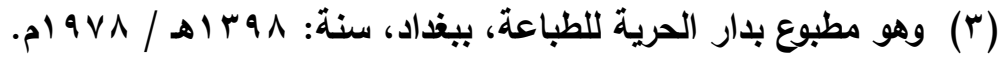


ثالث) : المبمث الأول: القراكات القرآنية والاهمات، وفيه مطالب: - - المطلب الأول: تعريف اللغة واللهجة، والفرق بينهما. - - المطلب الثاني: مصادر اللهجات العربية. - - المطلب الثالث: أهمية القراءات القرآنية في دراسة اللهجات العربية. رابهك : البمث الثثاني: لغة تميسم في القراكات العشّ الاتهاترة، وفيه مطلبان:

- المطلب الأول: القراءات التي يرجع الاختلاف فيها إلى الجانب الصوتي،

$$
\text { وفيه فرعان: }
$$

$$
\text { - الفرع الأول: أبواب الأصول. }
$$
- الفرع الثاني: فرش سورة البقرة. -المطلب الثاني: القراءات التي يرجع الاختلاف فيها إلى الجانب الصرفي. خامساك : الخاتمة : وفيها أهم النتائج. سادساك: الفهارسى: وفيها:1 - فهرس الآيات القرآنية.

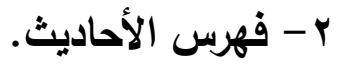


r- فهرس المصادر والمراجع ·

ع - فهرس الموضوعات .

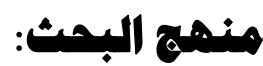

نهجت في كتابة هذا البحث المنهج الاستقرائيّ الوصفيّ، وإقصرت على أبواب الأصول، وسورة البقرة كنموذج لهذه الدراسة.

إبراs|ت البمشث:

ا - إذا نقلت من مصدر بالنص جعلت المنقول بين حاصرتين هكذا " " ثم أحلت على المصدر في الهامش، وإذا كان النقل بالمعنى أو بتصرف قلت: انظر. مع ذكر الجزء والصفحة. r - عزوت الآيات القرآنية إلى سورها في المتن بذكر اسم السورة ورقم الآية، واعتمدت العد الكوفي. ب- كتبت الآيات بالرسم العثماني، على ما في مصحف مجمع الملك فهر بالمدينة المنورة. ع - خرجت الأحاديث من الكتب المعتمدة. ه - وضعت فهارس فنية على النحو الموضح في الخطة .

ومن الآه أستمد العمن فهو هسبي ومليه اتكالي، وصالى الآله وسلم

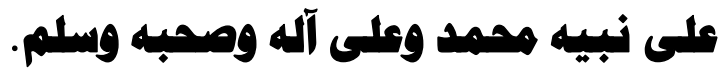




\section{التمبمهيد}

\section{أولأ: أشهر القبائل في الاهبات العربية:}

قال أبو نصر الفارابي في أول كتابه المسمى (الحروف) : كانت قريشٌ أجودَ العرب انتقاءً للأفَصح من الألفاظ، وأسهلها على اللسان عند النُّطْ، وأحسنها مسموعاً، وأبينها إبانَة عما في النفس، والذين عنهم نُقِلت اللغة العربية ويهم اقتُشُي وعنهم أُخِذَ اللسانُ العربيٌّ من بين قبائل العرب هم: قيس، وتميم، وأسد، فُان هؤلاء هم الذين عنهم أكثرُ ما أُخِذ ومعظمه، وعليهم هُ اتكُّل في الغريب وفي الإعراب والتَّصنريف، ثم هذيل ويعض كِنانة، ويعض الطائيين، ولم يؤخذ عن غيرهم من سائر قبائلهم. ويالجملة فإنه لم يؤخذ عن حضرَيٍٍ قط، ولا عن سكَّان البَرَاري ممن كان يسكنُ أطرافَ بلادِهم المجاورة لسائر الأمم الذين حولهم، فِإنه لم يؤخذ لا مِنْ

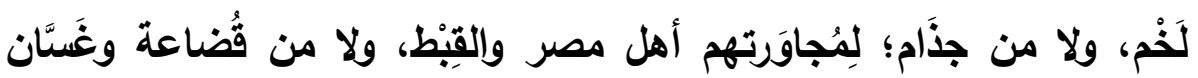
وإياد؛ لمجاورتهم أهل الشام وأكثرهم نصارى يقرؤون بالعبرانية، ولا من تغلب؛ فإنهم كانوا بالجزيرة مجاورين لليونان، ولا من بكر؛ لمجاورتهم للقبط والفرس، ولا من عبد القيس وأزد عمان؛ لأنهم كانوا بالبحرين مُخالطين للهِند والفُرس، ولا من بني حنيفة وسكان اليمامة، ولا من ثقيف وأهل الطائف؛ لمخالطتهم تجار اليمن المقيمين عندهم، ولا من حاضرة الحجاز؛ لأن الأين نقلوا اللغة صادفوهم حين ابتدؤوا ينقلون لغةَ العرب قد خالطوا غيرهم من 


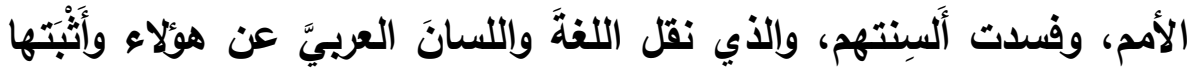
في كتاب فصيَّرها عِلْماً وصناعة هم أهلُ البصرة والكوفة فقط من بين أمصار

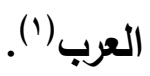

وقال ثُعب في أماليه: " ارتفعت قريشُّ في الفصاحة عن عَنْعَنَة تميم، وكثكثة ربيعة، وكسكسة هوازن، وتضجع قيس، وعجرفية ضبة، وتلتلة

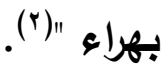

" روى أبو عبيد من طريق الكلبي عن أبي صالح عن ابن عباس قال: نزل القرآن على سبع لغات، منها خمسُ بلغة العَجُز من هوازن، وهم الذين يقال لهم غُلْيا هوازن، وهم خمس قبائل أو أربع، منها: سعد بن بكر، وجُشَّمَ بن بكر، ونَصْر بن معاوية، وثُقيف.

قال أبو عبيد: وأحسب أفصحَ هؤلاء: بني سعد بن بكر؛ وذلك لقول

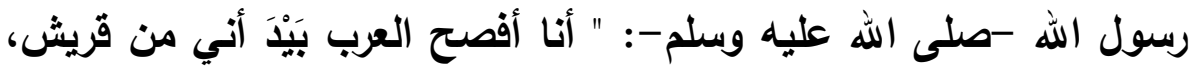
وأني نشأَتُ في بني سعد بن بكر "(")، وكان مُنْتَزَضعاً فيهم، وهم الذين قال

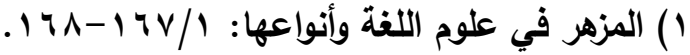

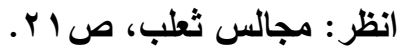

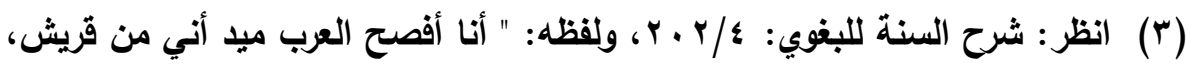

ونثأت في بني سعد بن بكر". 
فيهم أبو عمرو بن العلاء: " أفصحُح العرب عُلْيا هَوازن وسُقْلَى تميم "(1)، يعني: بني دارم(r).

وقد جاهت لغاتُ لأهلِ اليمن في القرآن معروفُةٌ، قال قوم: إنما هي لغة

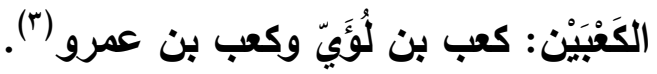

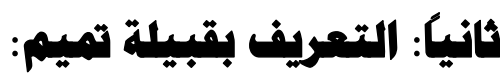

تميم: قبيلة عظيمة من العدنانية، تنسب إلى: تميم بن مرة بن مضر بن نزار، وتؤلف تميم تجمعاً كبيراً للعرب، فقد كانت قبائل عدة تنتمي إليها، وهي: كعب بن سعد بن زيل مناة، وحنظلة بن مالك بن زيد مناة، وهم البراجم، وينو دارم، وينو زلرة بن عدس، وينو أسيد، وعمرو بن تميم. وق امتلأت منهم البلاد، وكانوا أهل منعة وعدد ويأس ونجدة، وأصحاب فصاحة وشعر، وتؤلف تميم تجمعاً بدوياً في عاداته وتقاليده. وتميم تنتسب إلى أدّ بن طابخة بن إلياس بن مضر. ومن هنا قال فيهم

$$
\text { ابن حزم: " من أكبر قواعد العرب "(؛). }
$$

(1) (نظر: فضائل القرآن، للقاسم بن سلام، ص •ـ؟ب، والمرشد الوجيز، لأبي شامة،

$$
\text { ص } 9 \text { מ } 9 .
$$

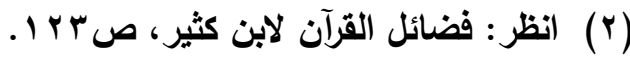

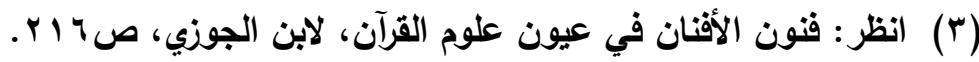

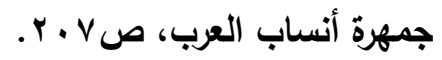


ولعل هذا التجمع الكبير من العرب الأي يضم جمهرة من القبائل دليل على أنها أقادت هذا الشمل على تراخي العصور والأحقاب.

وسكنت تميم المواطن الشرقية من أرض نجد، وهي تمتد فيها من الشمال إلى الجنوب، وجلها مفاوز وصحاري لايهتدي لمشاكثها، وماؤها من الآبار، كما يستفاد من تاريخ الطبري ('). وقد كانت تميم كلها بأسرها في اليمامة حيث جاء الإسلام. قال البكري: ثم مضوا حتى خالطوا أطراف هجر، ونزلوا مابينها ويين اليمامة، ووقعت طائفة منهم إلى عمان، وخالطوا عامر بن عبدالقيس في بلادهم قطر، وامتدت منازلهم إلى البحرين، فالأحساء، حيث نفذ بنو سعد بن زيل مناة بن تميم (r) (r) وقد حفلت كتب الأدب والتاريخ بإثارات تدل على مكانة تميم بين العرب في الجاهلية والإسلام، فكان منهم حكام الأسواق، ومن هؤلاء: مخاشن بن معاوية بن شريف، وابنه ريبعة، وأكثم بن صيفي، وحاجب بن زرارة، والأقرع بن حابس، وضمرة بن أبي حمزة. وفي الجانب الأدبي: كان في تميم من الثعراء غير واحد من المشاهير، فقيهم: أوس بن حجر، شاعر مضر في الجاهلية، وعبدة بن الطبيب، وعلقمة 
القحل، وسلامة بن جندل، ومالك ومتمم ابنا نويرة، والسليك بن السلكا، والعجاج، وابنه روئة، والفرزدق، وجريز .

قال أبو عبيدة: " ليس الإسلام مثل حظ تميم في الشعر، وأشعر تميم
جرير والفززدق "(1).

وإذا كان هذا حظ تميم في الشعر، فإن حظهم في الخطابة وإللسن لايقل عنه ، فمن خطبائهم: أكثم بن صيفي، وحاجب بن زلرارة، والأقرّع بن حابس، والأحنف بن قيس. وهي مع كل هذا مشهود لها بالفصاحة بين العرب، فقد ذكر المبرد في (الفاضل): " أن رسول الله -صلى الله عليه وسلم- ورد عليه الوفود فأقرأ الأخماس، كل خمس على لغته، فكان أعرب القوم تميم "(؟). وقال أبو عمرو بن العلاء : " أفصح العرب عليا هوازن وسفلى تميم "(r)" ومن أجل هذا ممن نقلت العربية عنهم، ويهم اقتدي، وعليهم اتكل في الغريب، وفي الإعراب والتصريف(؛).

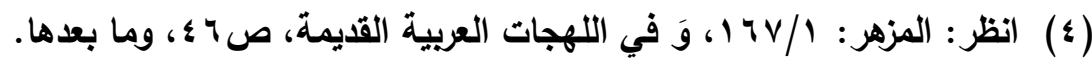




\section{المبيث الأول}

\section{القراءات القرآنية واللهبات، وفيه هطالب:}

\section{الإطلب الأول}

\section{تعريف اللغة والاهبة، والفرق بينهما:}

اللهجة : هي مجموعة من الصفات اللغوية، تنتمي إلى بيئة خاصة،

ويشترك في هذه الصفات أفراد هذه البيئة(').

والمقصود هي تلك اللهجات التي نقل إلينا طرف منها في كتب اللغة،

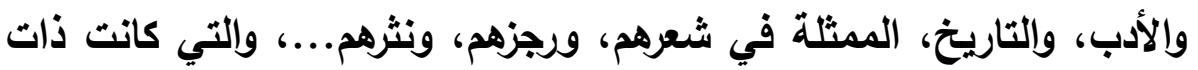
صفات خاصة تتميز بها القبائل العربية قبيل ظهور الإسلام.

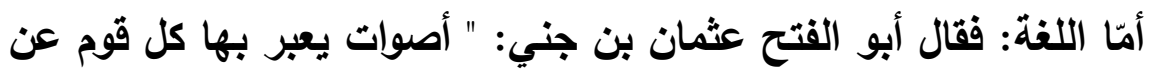
أغراضهم"(†). وقيل: هي مجموعة من اللهجات تنتمي إلى بيئة معينة.. والتعريف الأخير أوضح وأثشمل من الأول. والعلاقة بين اللهجة واللغة: هي العلاقة بين العام والخاص؛ لأن اللغة تثتمل على عدة لهجات، لكل منها ما يميزها، وجميع هذه اللهجات تثترك في مجموعة من الصفات اللغوية والعادات، التي تؤلف لغة مستقلة عن

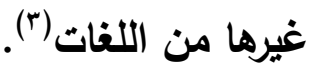

$$
\begin{aligned}
& \text { انظر: في اللهجات العربية، لإبراهيم أنيس، صل V ا. } \\
& \text { انظر : الخصائص، لابن جني: / / ؟ س. }
\end{aligned}
$$

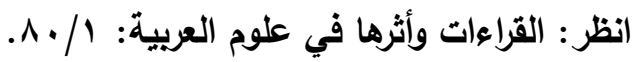


أما معنى اللهجة في الكتب التراثية القديمة: فالعرب القدماء حين كانوا يشيرون إلى تلك الفروق بين لهجات القبائل لم يستعملوا مصطلح (اللهجة) على النحو الأي نعرفه في الدرس اللغوي الحديث، بل إنّهم لم يستعملوه قط في كتبهم، وغاية ما وجدناه عندهم ما تردده معاجمهم من أنّ (اللهجة) هي: اللسان، أو طرفه، أو جرس الكلام، ولهجة فلان: لغته التي جبل عليها

فاعتادها، ونشأ عليها(') وإنّما كانوا يطلقون على اللهجة (لغة) أو (لغية)، ولعل ذلك راجع إلى أنهم لم يتوفروا على دراسة لهجة كاملة من لهجات القبائل التي كان يتكلمها الناس في حياتهم العادية، بل كل ملاحظاتهم إنّما تنصب على هذه الفروق اللهجية التي دخلت الفصحى (ץ).

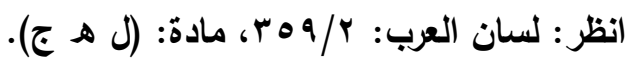

انظر : في اللهجات العربية، صل اله، وَ اللهجات العربية في القراءات القرآنية، لعبده

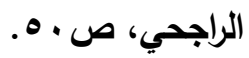




\section{الإhلب الثاني \\ مصادر الاهمات العربية}

للّهجات العربية العديد من المصادر، مثل:

(1)- كتب اللغات في القرآن، نحو: لغات القرآن للفراء(')، ولغات القرآن

$$
\text { للأصمعي(ץ)، ولغات القرآن لأبي زيد (ז). }
$$

r) - المعاجم: رغم أن كثيراً منها لم يهتم بعزو اللهجات إلى قبائلها.

وهناك أيضاً المعاجم الخاصة التي كانت تجمع مادة لغوية في موضوع واحد؛

إذ كان أصحابها يهتمون باللهجات، مثل: كتاب (المطر) لأبي زيد(؛)، وكتاب:

$$
\text { (الرحل والمنزل) لأبي عبيد(•). }
$$

ومما يعد من المعاجم الخاصة أيضاً: ما جاء في المشترك والمترادف، والأضداد، فالمشترك: إنما يجيء على لغتين متباينتين(")، والمترادف: إنما يكون " من واضعين وهو الأكثر، بأن تضع إحدى القبيلتين أحد الاسمين،

$$
\begin{aligned}
& \text { (1) انظر : الفهرست لابن النديم، ص \& ه. }
\end{aligned}
$$

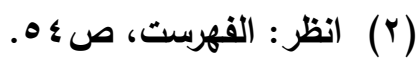

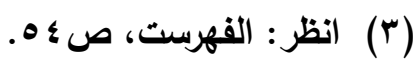

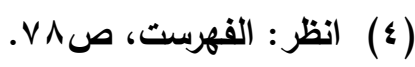

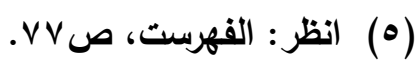

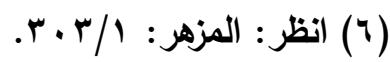


والأخرى الاسم الآخر للمسمى الواحد، من غير أن تشعر إحداهما بالأخرى، ثم

يشتهر الوضعان، ويخفى الواضعان "(').

وكذلك تعلل الأضداد باختلاف اللهجات، " فإذا وقع الحرف على معنيين متضادين فمحال أن يكون العربي أوقعه عليهما بمساواة منه بينهما، ولكن أحد المعنيين لحي من العرب، والمعنى الآخر لحي غيره، ثم سمع بعضهم لغة بعض فأخذ هؤلاء عن هؤلاء، وهولاء عن هؤلاء"(r). r)- تأتي بعد ذلك كتب النوادر، وهي مصدر طيب لاراسة اللهجات، مثل كتاب: النوادر لأبي زيد(). ع)- الأمثال: ودراستها تفيد الارس اللهجي؛ لأن الأمثال لغة الشعب التي يطلقها فور الحدث دون تصنع، وهي من هنا تعتبر مرآة صادقة للهجة، ويعتمد عليها في دراسة اللهجات اعتماداً كبيراً.

•)- الضرورة الشعرية: وهي في حاجة إلى دراسة جديدة تستقرئها وبردها إلى أصولها؛ لأن هذه التي يسمونها ضرائر تلجئ إليها طبيعة الثعر ليست إلا لهجات عربية، وقد صرّح بعضهم أن بعض هذه الضرائر لهجات، مثلما نجد عند أبي سعيد القرشي في أرجوزته في الضرائر:

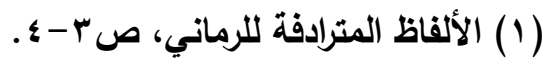

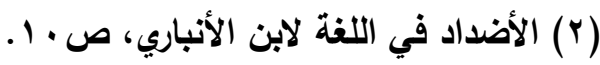

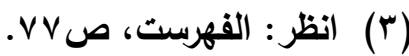


وريما تصادف الضرورة .بعض لغات العرب المشهورة(1) وهم يعدون من الضرائر: صرف الممنوع، وقصر الممدود، والوقف على المنون المنصوب بحذف الألف، وغير ذلك، وكل هذه الظواهر لهجات وردت بها قراعات قرآنية. 7) - كتب النحو، مثل: كتاب سيبويه، وإن كان يكتفي في كثير من الأحيان بذكر اللهجة دون تعيين أصحابها، إلا أن فيه ذكراً للقبائل التالية: الحجاز، تميم، أسد، فزارة، طيء، بكر بن وائل، ربيعة، قيس، هذيل، بنو العنبر. لكن معظم لهجاته تكاد تكون محصورة في: الحجاز، وتميم. أما النحاة اللذين اهتموا باللهجات اهتماماً كبيرًا فهم النحاة المتأخرون، مثل: ابن مالكك وشراح ألفيته، والسيوطي، وغيرهم. V) - المصدر البشري: إن للمصدر البشري أثر كبير في استقاء اللغة، فاللغويون العرب أخذوا مادتهم اللغوية عن طريقين: أ- الخروج إلى البادية والحياة بين البدو، كما يعرف عن الكسائي أنه لما عرض على حمزة خرج إلى البدو، فشاهد العرب، وأقام عندهم، حتى صار كواحد منهم (r). ب- الأعراب الأين عدّوهم فصحاء، وغالب هولاء الأعراب كانوا يقيمون بمدن العرلق، يختلف إليهم اللغويون في البصرة والحيرة ويغداد.

(1) انظر : الضرائر وما يسوغ للثاعر دون الناثر ، للألوسي، ص ؟ ؟.

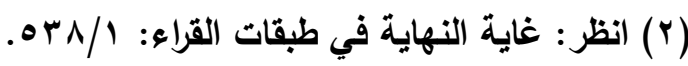


^)- القراءات القرآنية: وهي أهم وآصل مصادر اللهجات العربية(1)، وسنتحدث عن أسباب ذلك بالتفصيل في المطلب الرابع من هذا المبحث.

\section{الإطب الثالث}

\section{أهمية القراءات القرآنية في دراسة اللهبات العمبية:}

تعتبر القراعات القرآنية أهمّ وآصل مصادر اللهجات العربية، وذلك

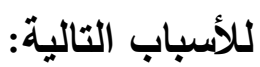

أوّلاً: لوثاقتها وصحة ثبوتها، بخلاف جميع المصادر الأخرى، فالقراعات على خلاف باقي المصادر لا تكتفي بمجرد نقل المسموع من كلام العرب، بل تقرنه بصفة أدائه كذلك، فمنهج علم القراءات في طريقة نقلها يختلف عن كل الطرق التي نقلت بها المصادر الأخرى: كالثعر والنثر، بل يختلف عن طرق نقل الحديث، فالقراءة لا تكتفي في النقل بالسماع، بل لا بدّ من شرط التلقي والعرض، وهما أصح الطرق في النقل اللغوي.

ثانياً: لتتوعها وكثرة مادتها.

ثالثاً: علم أصحاب القراعات بعلوم العربية، فبالإضافة إلى أنّ أصحاب القراءات كانوا إلى جانب شهرتهم بالضبط والدقة والإتقان على معرفة

واسعة بالعربية ووجوهها(؟).

$$
\text { (1) انظر: اللهجات العربية في القراءات القرآنية، ص • • و وما بعدها. }
$$


رابعاً: عدالة أئمة القراءة وتدينهم، بخلاف أئمة اللغة فإنّ هذه الصفة لا تطرّد

وأما أثر القراعات في اللهجات العربية القديمة فهو واضح كل الوضوح، وهذا الأثر يتجلى في العديد من الأمور، منها ما يلي: أ- لقد كان للقرآن الكريم وقراء|ته الأثر الواضح في تهذيب لهجات الكثير

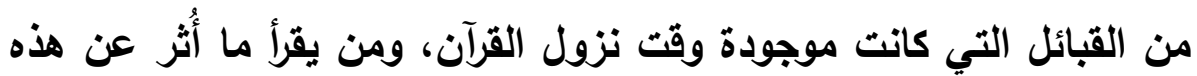
القبائل من شعر ونثر يلحظ ذلك جلياً. ب- لقد كان لاختلاط العرب بغيرهم من الأجناس المختلفة أصحاب اللهجات المتعددة الأثر الواضح في ضياع اللهجات العربية القديمة، ولولا القرآن

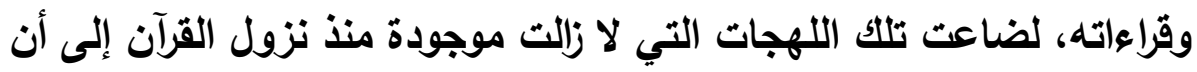

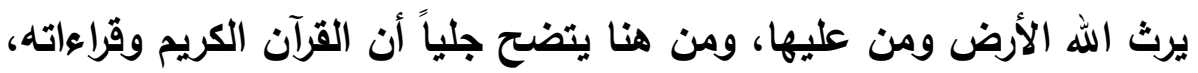

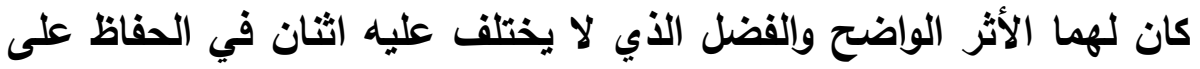
الكثير من اللهجات العربية القديمة، التي أصبحت في ذمة التاريخ. ج- لولا القرآن الكريم وقراءاته، ما عُرفت كثير من اللهجات، التي لا زال يرددها وينطق بها الملايين من شتى بقاع الارض بما فيهم العربي، وغير

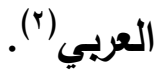
$* \quad * \quad *$

$$
\begin{aligned}
& \text { انظر : اللهجات العربية في القراءات القرآنية، ص \& ^، وما بعدها. }
\end{aligned}
$$

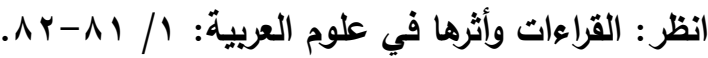




\section{الابمشث الثاني}

لغة تميم في القراءات العشر المتواترة، وفيه مطابلان: الإطبا الأول

القراءات التي يرجع الاختلاف فيها إلى البانب الصولي

$$
\text { وفيه فرعان }
$$

\section{الفرع الأول: أبواب الأهمل}

ويتمثل ذلك في القضايا الآتية:

$$
\text { ب أ - ظاهرة الإدغام. }
$$

و - ظاهرة قلب السين صاداً عند أريعة أحرف: الطاء، وإلهاء القاف، والغين،

$$
\text { والخاء. }
$$

\section{أولاً: ظاهرة الإدغام:}

الإظهار والإدغام إحدى الظواهر اللغوية التي اهتم بها العلماء قديماً وحديثاً، ووضعوا لها الكثير من الضوابط وإلقواعد.

وإختف العلماء في تعليلها وتفسيرها، وأي القبائل العربية كانت تميل إلى النظق بالإظهار، وأيها كانت تميل إلى الإدغام. 
ويالاستقراء يتضح أن قبيلة تميم من القبائل التي كانت تميل إلى الإدغام('). والإدغام لغة : الإدخال، يقال: أدغمت اللجام في فم الدابة، أي: أدخلته فيه(ץ). واصطلاحاً: التقاء حرف ساكن بحرف متحرك بحيث يصيران حرفاً واحداً مشدداً (r).

والإظهار هو الأصل، حيث لا يحتاج إلى سبب في وجوده، أما الإدغام فلا يكون إلا بسبب، والقصد منه: إرادة التخفيف. وأسباب الإدغام ثُلاثة: التماثل، أو التقارب، أو التجانس. فالتماثل: أن يتفقا مخرجاً وصفة، كالباء في الباء، والتاء فِي التاء، وسائر المتماثلين. والتجانس: أن يتفقا مخرجاً ويختلفا صفةً، كالذال في الثاء، وهي والثاء في الظاء، والتاء في الدال.

والتقارب: أن يتقاريا مخرجاً، أو صفة، أو مخرجاً وصفة(؛). وهناك من جعل التقارب والتجانس بمعنيً واحد، كالإمام الشاطبي -رحمه الله-، فإن قوله: " وإن كلمة حرفان فيها تقاربا .. "(ه) يشمل المتقارب والمتجانس.

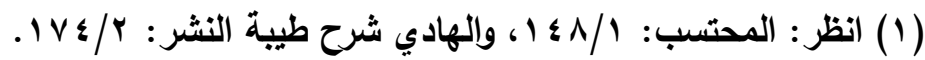

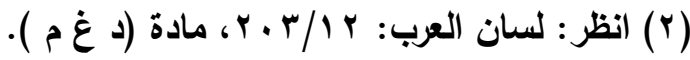

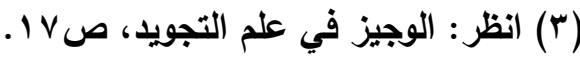

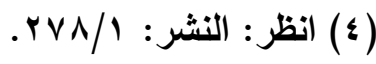

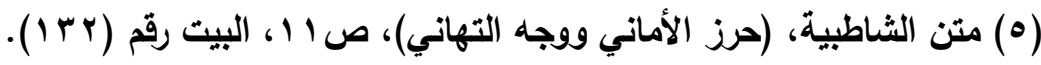


والإدغام ظاهرة صوتية تحدث بسبب تأثز الأصوات المتجاورة بعضها ببعض، وكثيراً ما يحدث ذلك في البيئات البدائية حيث السرعة في النطق ببعض الكلمات، ومزج بعضها ببعض، فلا يعطى الحرف حقه الصوتي من تجويد في النطق به، لألك يمكن أن نتصور أن الإدغام كان أكثر شيوعاً في لهجات القبائل البدوية، كقبيلة تميم، كما أن البيئة العراقية قـ نزح إليها العديد من القبائل التي هي أقرب إلى البداوة ممن عاثوا في البيئة الحجازية. ولعل ذلك هو الذي جعل قراء الكوفة والبصرة والثام أكثر نقلاً للإدغام من قراء مكة، والمدينة؛ نظراً لأن البيئة الحجازية كانت بيئة استقرار، وييئة حضارة نسبياً، يميل الناس فيها إلى التأني في النطق، وإلى تحقيق الأصوات

وعدم الخلط بينها (1).

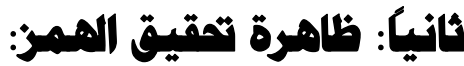

الهمزة من أصعب الحروف في النطق؛ وذلك لبعد مخرجها؛ إذ تخرج من أقصى الحلق، كما اجتمع فيها صفتان من صفات القوة: وهما: الجهر، والشدة .

واللهزة صوت صامت حنجري انفجاري، وهو يحدث بأن تسد القتحة الموجودة بين الوترين الصوتيين وذلك بانطباق الوترين انطباقاً تاماً، فلا يسمح للهواء بالنفاذ من الحنجرة، فيضغط الهواء فيما دون الحنجرة، ثم ينفرج الوتران فينفذ الهواء من بينهما فجأة محدثاً صوتاً انفجارياً(؟).

$$
\begin{aligned}
& \text { (1) انظر : القراعات وأثرها في علوم العربية: 11/1، وما بعدها. }
\end{aligned}
$$

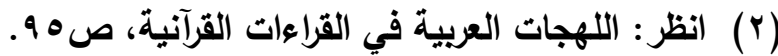


ومن الحقائق العامة أن الهمز كان خاصة من الخصائص البدوية التي اشتهرت بها قبائل وسط الجزيرة العربية وشرقيها: تميم وما جاورها(')، وأن تخفيف الهمز كان خاصة حضرية امتازت بها لهجة القبائل في شمال الجزيرة

وغرينها.

جاء في لسان العرب قول عيسى بن عمر: " ما آخذ من قول تميم إلا

بالنبر، وهم أصحاب النبر، وأهل الحجاز إذا اضطروا نبروا "(؟).

وإذا كانت القبائل البدوية التي تميل إلى السرعة في النطق، وتسلك أيسر السبل إلى هذه السرعة فإن تحقيق الههز كان في لسان الخاصة التي تخفف من عيب هذه السرعة، أي أن الناطق البذوي تعوّد النبر في موضع الهمز، وهي عادة أملتها ضرورة انتظام الإيقاع النطقي، كما حكمتها ضرورة الإبانة عما يريده من نطقه لمجموعة من المقاطع المتتابعة السريعة الانطلاق على لسانه، فموقع النبر في نطقه كان دائماً أبرز المقاطع، وهو ما كان يمنحه كل اهتمامه وضغطه. أما القبائل الحضرية فعلى العكس من ذلك، اذ كاتت متأنية في النطق، متئدة في أدائها، أو إذا لم تكن بها حاجة إلى التماس المزيد من مظاهر الأناة ، فأهملت همز كلماتها، واستعاضت عن ذلك بوسيلة أخرى: كالتسهيل،

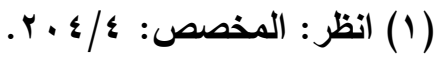

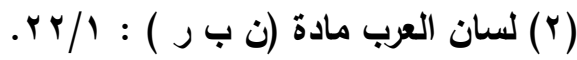


والإبدال، والإسقاط، والنقل، وقد وردت القراءات القرآنية الصحيحة بكل

ذلتك (').

\section{ثالثأ: ظاهرة الإمالة:}

القتح والإمالة هما إحدى الظواهر اللغوية التي كانت متفشية بين القبائل

$$
\text { العربية منذ زمن بعيد قبل الإسلام . }
$$

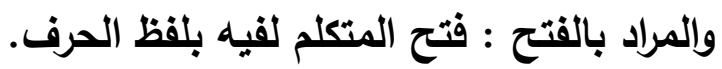

والإمالة لغة : التعويج، يقال: أملت الرمح ونحوه إذا بلها عوجته عن استقامته.

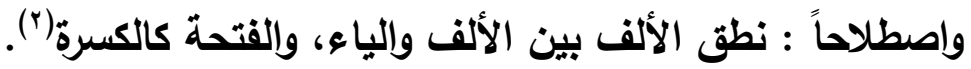
تنقسم إلى قسمين: كبرى، وصغرى.

فالكبرى: أن تقرب الفتحة من الكسرة، والألف من الياء، من غير قلب

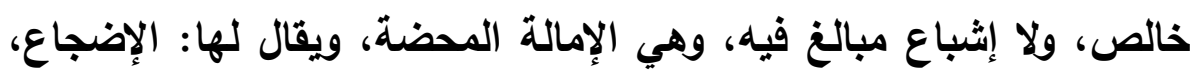
والبطح.

والصغرى: هي ما بين القتح والإمالة الكبرى، ويقال لها: (بين بين) أي

بين الفتح والإمالة الكبرى (ّ). ويالتبع يمكنتا أن نتسب الفتح إلى القبائل العربية التي كانت مساكنها

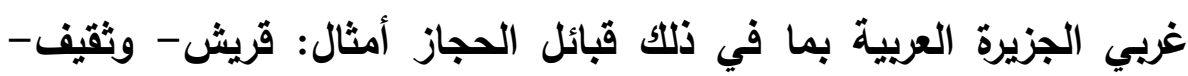

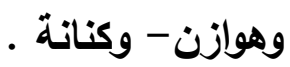

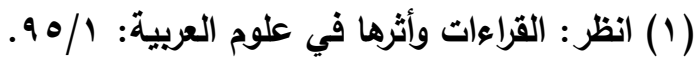

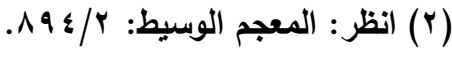

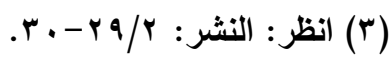


وأن نتسب الإمالة إلى القبائل التي كانت تعيش وسط الجزيرة، وشرقيها، أمثال: تميم - وقيس - وأسد - وطيء - ويكر بن وائل - وعبد القيس (1).

ومن القراء من قرأ بالإمالة الكبرى أو الصغرى، ومنهم من قرأ بالقتح(ب). وتتلخص أسباب الإمالة فيما يلي : 1 - كسرة موجودة في اللفظ قبليّة، أو بعدية، نحو: (الناس والنار) . r - r كسرة عارضة في بعض الأحوال .

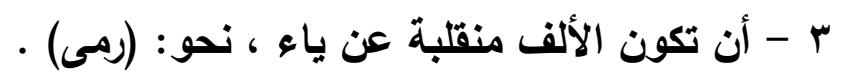
؛ - ما أثببه المنقلب عن الياء، نحو: (موسى وعيسى) • ه- مجاورة إمالة، وتسمى إمالة لأجل إمالة ، نحو : إمالة نون (نأى) . צ- أن تكون الألف رسمت ياء وإن كان أصلها الواو، نحو : (والضحى) .

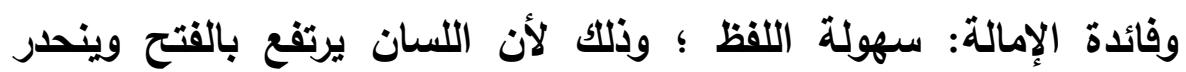
بالإمالة، والاتحدار أخف على اللسان من الارتفاع (") . رابعا: ظاهرة كسر هاء الكناية من فير صلة: في نحو: (عليه) وَ (إليه)، وهي لغة بني تميم(؛) .

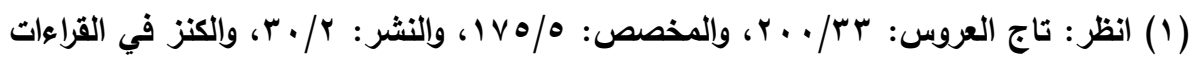

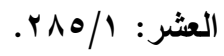

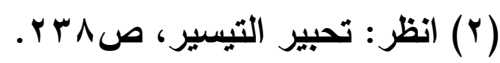

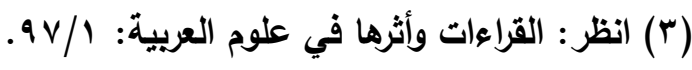

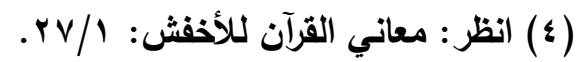


وهاء الكناية: هي هاء الضمير التي يكنى بها عن المفرد المذكر الغائب، وإذا وقعت بعد ساكن وقبل متحرك: فلا يخلو الساكن قبل الهاء من أن يكون ياء، أو غيرها، فإن كان ياءً: فإن ابن كثير يصل الهاء بياء في الوصل، وإن كان غير ياء : وصلها ابن كثير أيضاً بواو، والباقون: يكسرونها بعد الياء، ويضمونها بعد غيرها من غير صلة، إلا أن حفصاً يضمها في

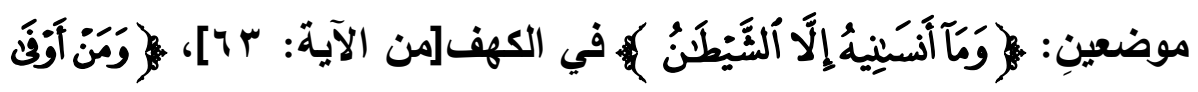

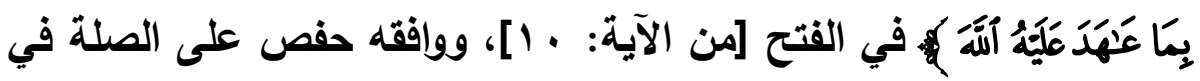

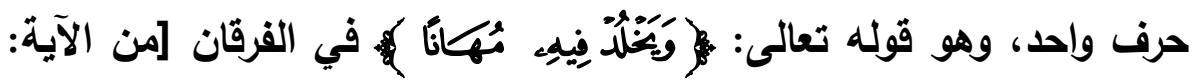
(1) $[79$

\section{خامسك : ظلاهرة الإسكان في هاء (هو) و (هي) إذا جادت بعد الهاو}

\section{: pyllg sling}

وقا قرأ قالون وأبوعمرو وأبو جعفر والكسائي: بإسكان الهاء من (هو) وَ (هي) إذا كان قبلها واو أو فاء أو لام حيث وقع، والباقون: يحركون

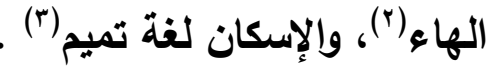

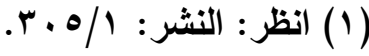

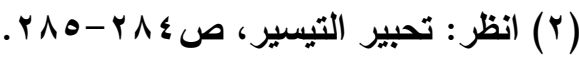

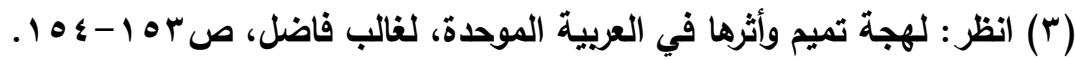




\section{سادسك: ظاهرة قالب السين صادا عند أربعة أحرف: الطاء، والقاف،} والغين، والغاء :

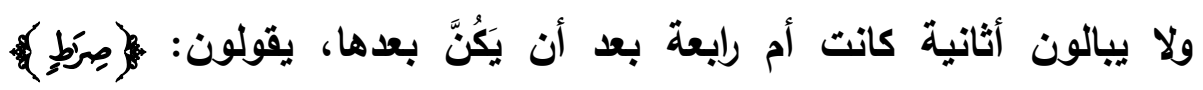

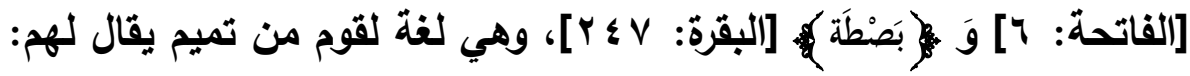
بَلْعَنْبر (1)

وقد قرأ نافع والبزي وأبوعمرو وابن عامر وعاصم والكسائي وأبوجعفر وروح

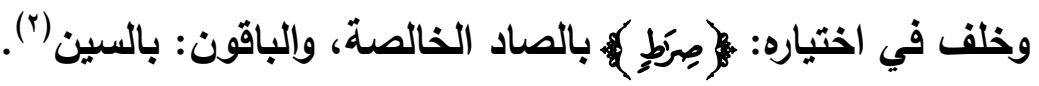

\section{الفرع الثاني: فرش سورة البقرة}

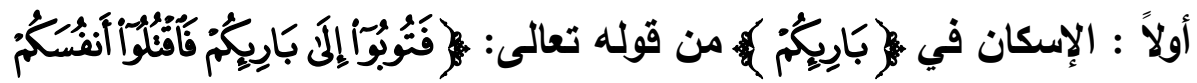

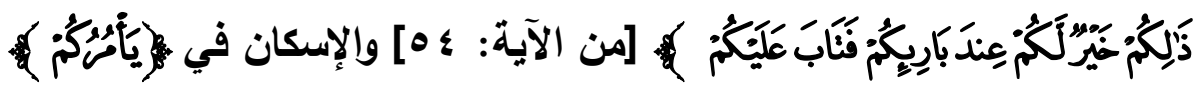

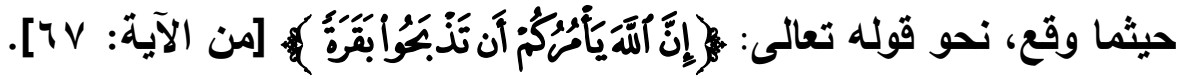
قرأ الدوري عن أبي عمرو، بثلاثة أوجه : الأول : إسكان الهمزة من (بارئكم) والراء من (يأمركم). والثاني: اختلاس الحركة فيهما .

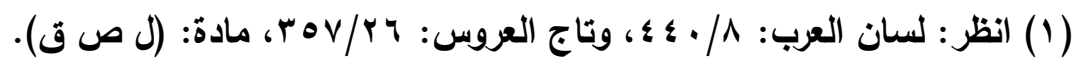

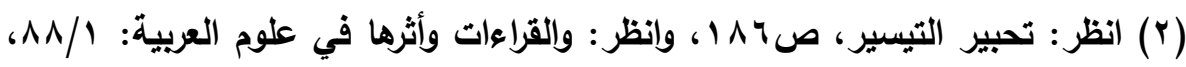

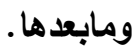


في القراعات العشرّ المتواترة

والثالث : الحركة الخالصة.

وقرأ السوسي بوجهين: بالإسكان، ويالاختلاس، وقرأ الباقون: بالحركة

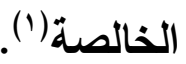

ووجه من قرأ بالإسكان: التخفيف، وهو لغة بني أسد، وتميم(ץ).

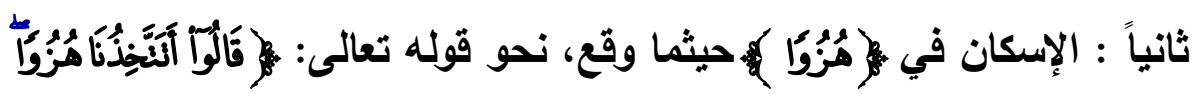

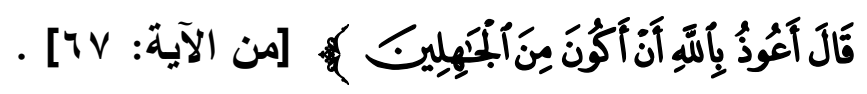

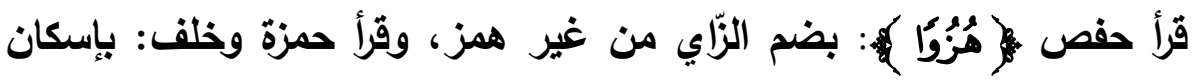

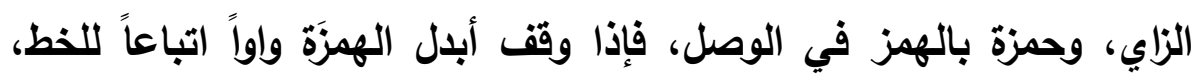
والباقون: بالضم والهمز (r). والإسكان لغة تميم وأسد وقيس(4).

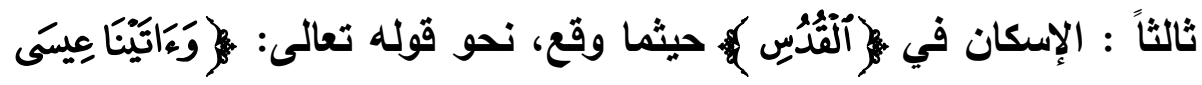

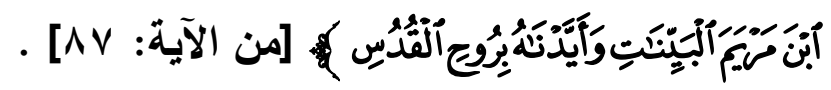

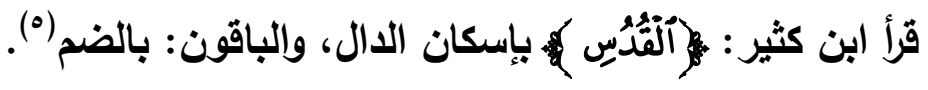

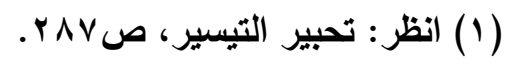

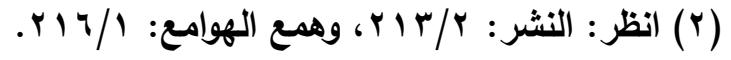

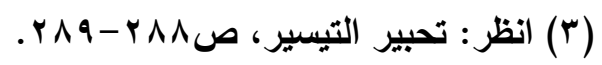

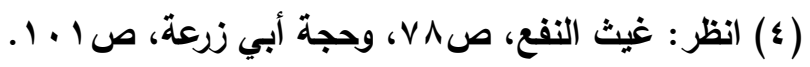

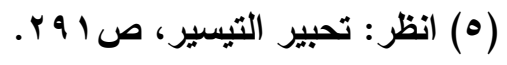


ووجه الإسكان: التخفيف كي لا تتوالى ضمتان، وهو لغة تميم(').

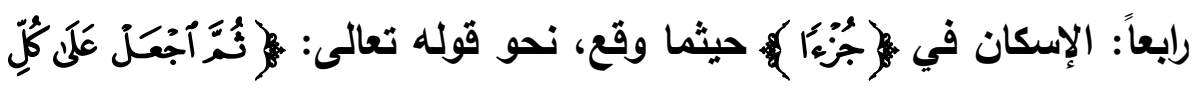

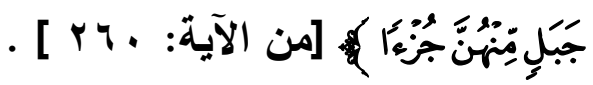

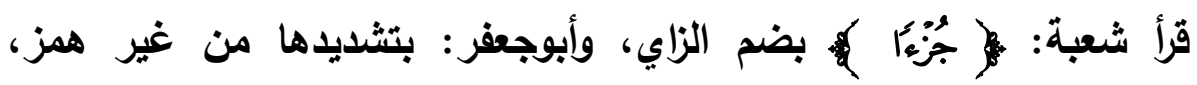
والباقون: بإسكانها(؟)، والإسكان هو الأصل، وهو لغة تميم وأسد(ז).

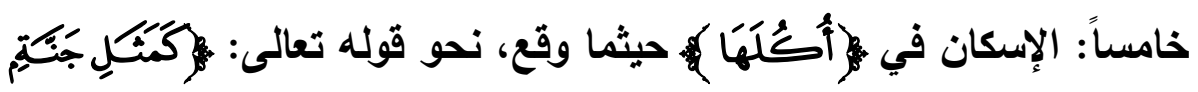

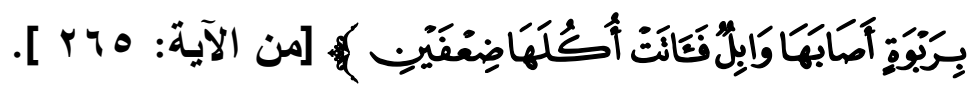
قرأ نافع وابن كثير وأبوعمرو: بإسكان الكاف، والباقون: بالضم(؛). والإسكان والضم لغتان في كل اسم على ثثلاثة أحرف أوله مضموم، والإسكان هو الأصل ، وهو لغة تميم وأسد (•)

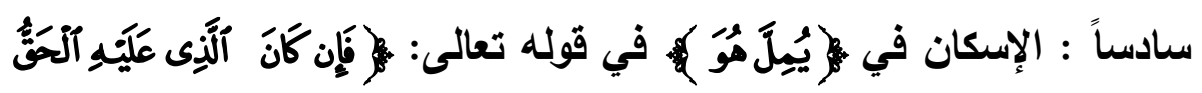

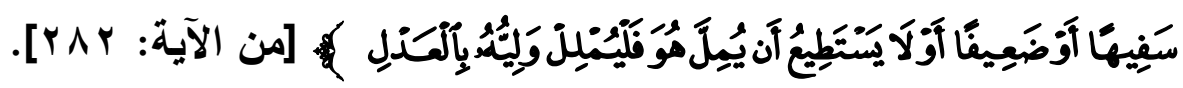

$$
\begin{aligned}
& \text { (1) انظر : لهجة تميم، ص به 1). }
\end{aligned}
$$

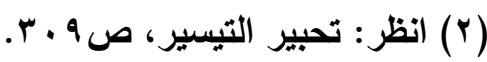

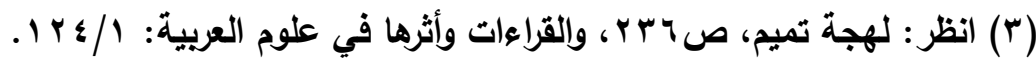

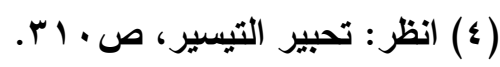

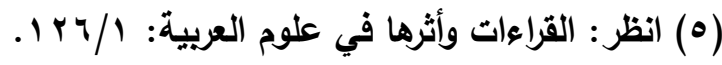


قرأ أبو جعفر بالإسكان، والباقون يحركون الهاء(')، والإسكان لغة تميم(ץ).

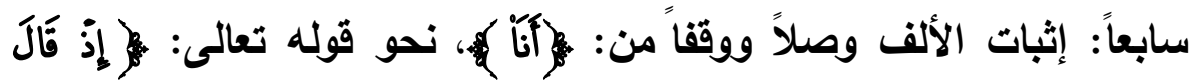

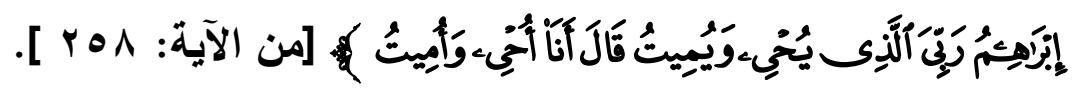

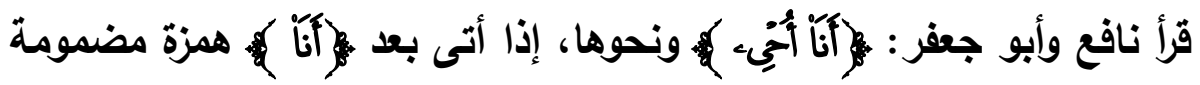
أو مفتوحة: بإثبات الألف في الحالين، وهي لغة تميم(")، والباقون: يحذفون

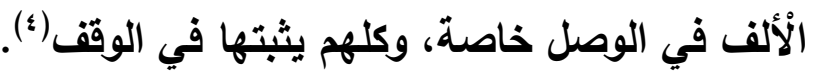

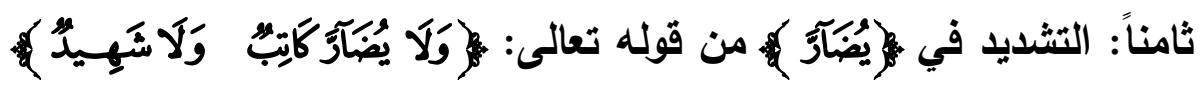
[من الآية: r r r ]

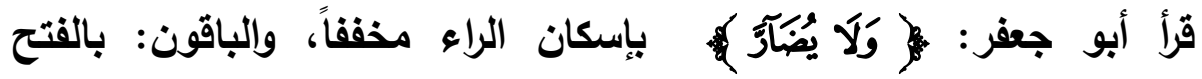
والتشديد(•)، وهي لغة تميم(")

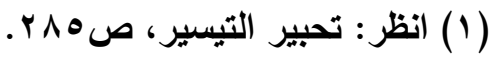

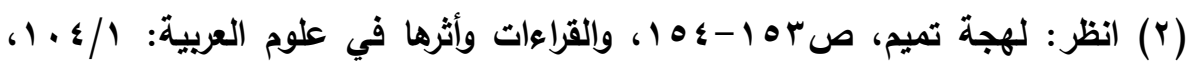
ومابعد ها.

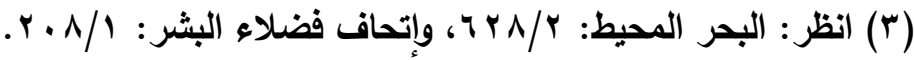

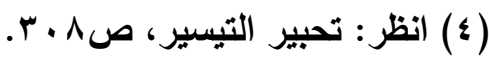

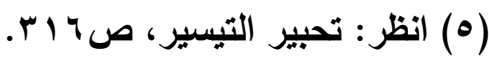

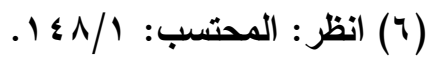




\section{الإلب الثاني}

\section{القراكات التي يرجع الاختلاف فيها إلى الجانب الصرفي}

والمراد بالجانب الصرفي: ما كان فيه التغيير في وزن الكلمة، وفي حركاتها، في أوائلها وأواسطها، مما شأنه الميزان الصرفي وليس الحكم النحوي. أولاً : فتح السين من: إيَّسَبُ ) كيف وقع وكان فعلاً مضارعاً، نحو قوله

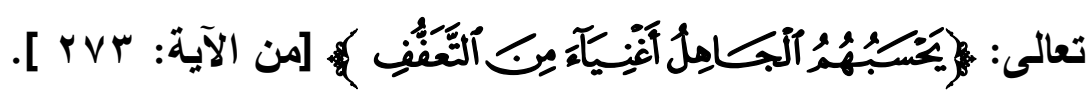

قرأ ابن عامر وعاصم وحمزة وأبو جعفر : بفتح السين(')، وهو لغة تميم(؟).

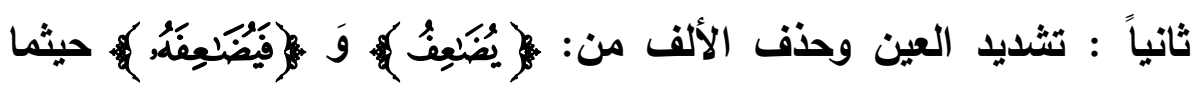
وقعت.

قرأ ابن كثير وابن عامر وأبو جعفر ويعقوب : بتشديد العين من غير ألف()، وهي لغة تميم(؟).

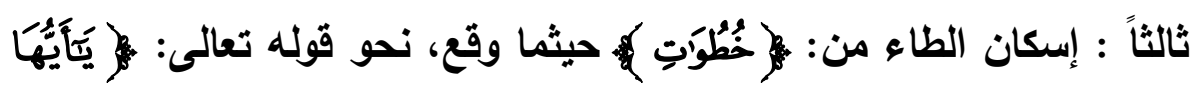

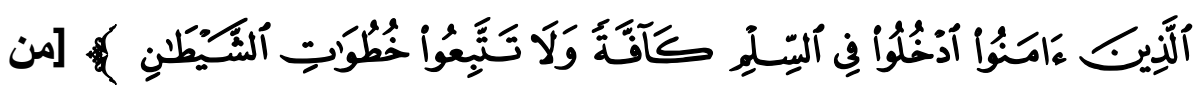

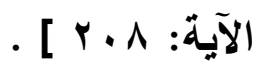

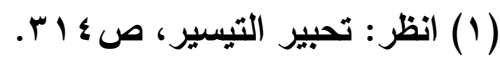

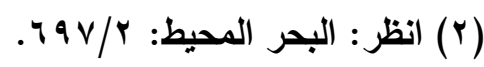

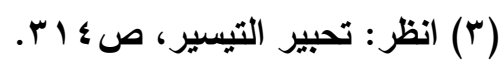

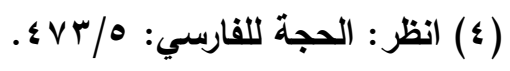


قرأ قتبل وحفص وابن عامر والكسائيّ وأبو جعفر ويعقوب: بضم الطاء،

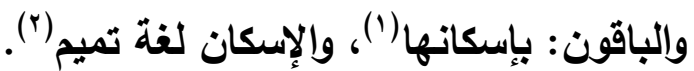

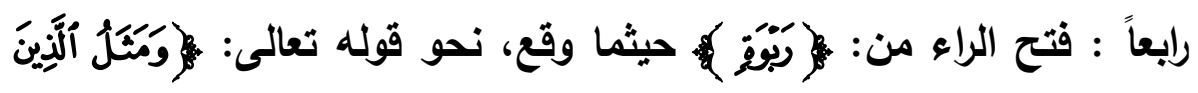

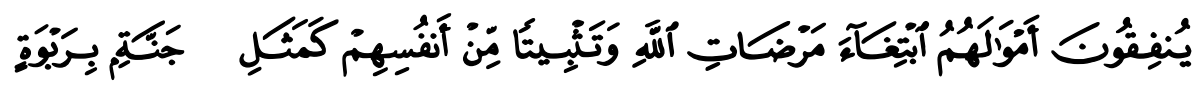

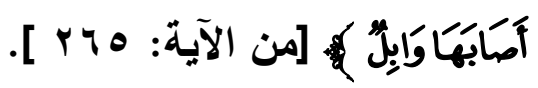

قرأ عاصم وإبن عامر: بفتح الراء، وهي لغة تميم()، والباقون: بضمهاء().

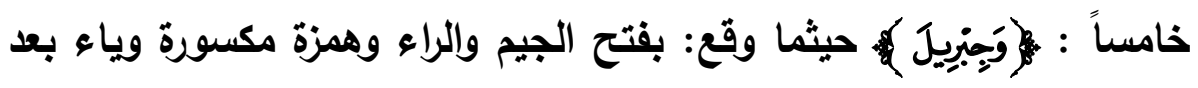

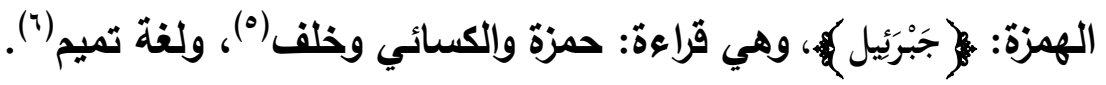

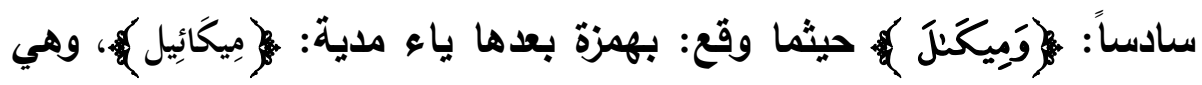
قراءة: ابن كثير وابن عامر وشعبة وحمزة والكسائي وخلف في اختياره(V)،

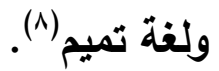

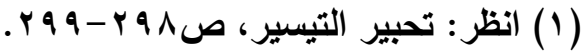

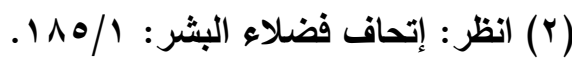

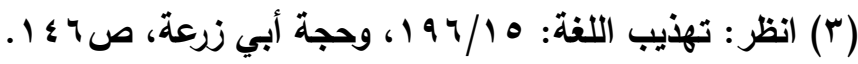

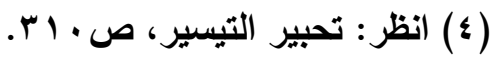

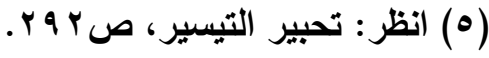

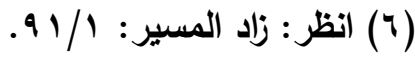

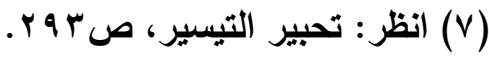

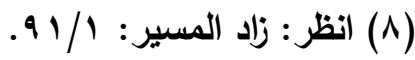




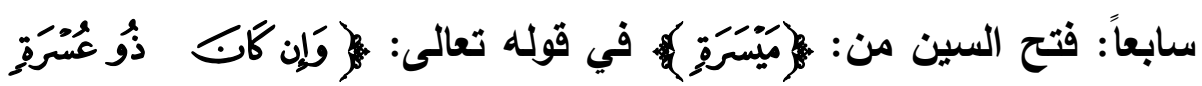

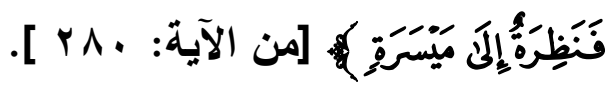

قرأ نافع: بضم السين، والباقون: بفتحها(')، وهي لغة تميم(r).

(1) انظر : تحبير التيسير، صه اس.

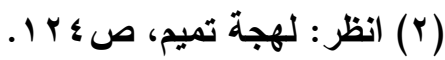




\section{النغاتمهـة}

الحمد لله رب العالمين ، والصلاة والسلام على أشرف المرسلين، نبينا محمد، وعلى آله وصحبه أجمعين، ويعد:

فإني أحمد الله تعالى على ما يسره لي من جمع مادة هذا البحث، وأسجل في ختامه أبرز النتائج التي توصلت إليها : • يسير الله على هذه الأمة بإنزاله القرآن الكريم على سبعة أحرف. • تعدد مصادر اللهجات العربية: كالمعاجم، وكتب اللغات في القرآن، والنوادر، والأمثال، وغيرها.

• تعدّ القراعات القرآنية أهمّ وآصل مصادر اللهجات العربية؛ وذلك لوثاقتها، وتنوعها، وعلم أصحابها بالعربية، وعدالتهم . • للقراعات القرآنية دور عظيم في حفظ لغات العرب ولهجاتها، التي لا زالت موجودة منذ نزول القرآن إلى أن يرث الله الأرض ومن عليها. • مكانة لهجة تميم؛ حيث تعد رافضاً مهماً من روافد اللغة العربية الفصحى. وآخر دومانا أن العمد لاله وب العلاين. 


\section{فهرس المصادر والمراجع.}

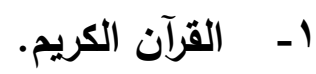

r - - إتحاف فضلاء البشر في القراءات الأربعة عشر، المؤلف: أحمد بن محمد بن أحمد الدمياطيّ، الشهير بالبناء (ت: VII Vه)، المحقق: أنس مهرة، الناشر : دار الكتب العلمية-لبنان.

r- - الأضداد في اللغة، المؤلف: أبو بكر محمد بن القاسم بن محمد الأنباري النحوي، المحقق: محمد أبو الفضل إبراهيم، الناشر: المكتبة

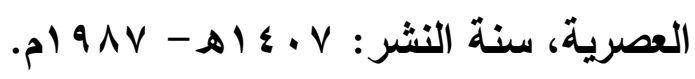

ـ- الأغاني، المؤلف: أبو الفرج علي بن الحسين الأموي الأصفهاني (ت: جه هـ)، الناشر: دار إحياء التراث العربي، بيروت، الطبعة: الأولى، $.81 \leqslant 10$

هـ الألفاظ المترادفة المتقاربة المعنى، المؤلف: أبو الحسن علي بن عيسى الرماني، المحقق: فتح الله صالح المصري، الناشر: دار الوفاء،

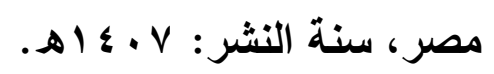

7- البحر المحيط في التفسير، المؤلف: أبو حيان محمد بن يوسف بن علي بن حيان الأندلسي (ت: 0 ؛ Vه)، المحقق: صدقي محمد جميل، الناشر : دار الفكر -بيروت.

V- - تاج العروس من جواهر القاموس، المؤلف: محمّد بن محمّد بن عبد

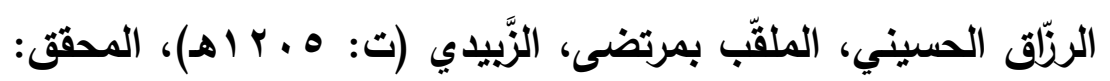

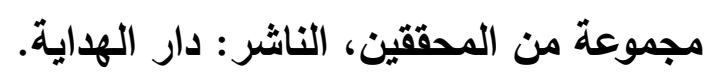
^- تاريخ الرسل والملوك، المؤلف: محمد بن جريز بن يزيد بن كثير بن 
غالب الآملي، أبو جعفر الطبري (ت: · اسهـ)، الناشر: دار التراث،

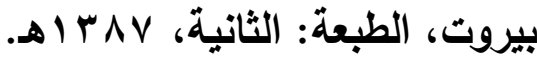
9- تحبير التيسير في القراءات العشر، المؤلف: محمد بن محمد بن يوسف، أبو الخير ابن الجزري (ت: بr^ه)، المحقق: د/أحمد محمد

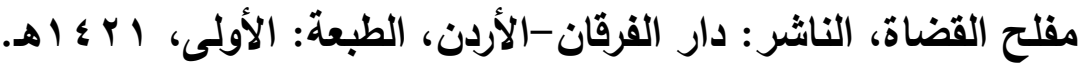
• 1 - تهذيب اللغة، المؤلف: محمد بن أحمد بن الأزهري الهروي، (ت:

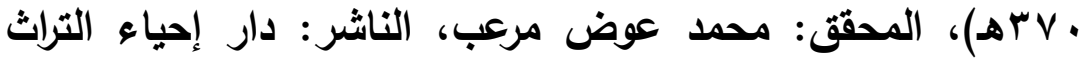
العربي-بيروت، الطبعة: الأولى، 1 ـ. . بم. 1 - - جمهرة أنساب العرب، المؤلف: أبو محمد علي بن أحمد بن سعيد بن حزم الأنلالسي القرطبي الظاهري (ت: وهـهـ) المحقق: لجنة من العلماء، الناشر: دار الكتب العلمية، بيروت، الطبعة: الأولى، $.19 \wedge \mu / 1 \varepsilon \cdot r$ r ا - حجة القراءات، المؤلف: عبد الرحمن بن محمد ابن زنجلة (ت: حوالي r r • هـ)، المحقق: سعيد الأفغاني، الناشر: دار الرسالة. با - الحجة للقراء السبعة، المؤلف: الحسن بن أحمد أبو علي القارسيّ (ت: هـVVV

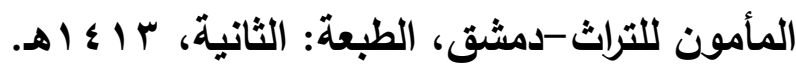
ع ا - حرز الأماني ووجه التهاني في القراءات السبع، المؤلف: القاسم بن فيره بن خلف بن أحمد الرعيني، أبو محمد الشاطبي (ت: ، 9هـ)، المحقق: محمد تميم الزعبي، الناشر: مكتبة دار الهـى ودار الغوثاني

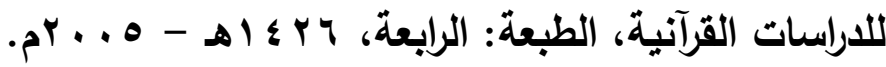


ه 1 - الخصائص، المؤلف: عثمان بن جني الموصلي (ت: r ب به)، الناشر: الهيئة المصرية العامة للكتاب، الطبعة: الرابعة.

צ ا - زاد المسير في علم التفسير، المؤلف: عبد الرحمن بن علي بن محمد الجوزي (ت: V9 Vه)، المحقق: عبد الرزاق المهذي، الناشر: دار

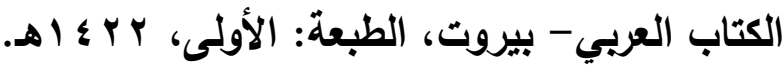

IV الفراء البغوي الشافعي (ت: 1 ا0هـ)، المحقق: شعيب الأرنؤوط، ومحمد زهير الشاويش، الناشر: المكتب الإسدلامي - دمشث، بيروت،

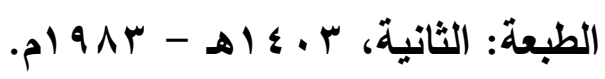

1 1 - الضرائر وما يسوغ للثاعر دون الناثز، المؤلف: محمود شكري الألوسي، المحقق: محمد بهجة البغدادي، الناشر: المكتبة العربية،

$$
\text { العراق. - مان. }
$$

9 ا - غاية النهاية في طبقات القراء، المؤلف: ابن الجزري، محمد بن محمد

$$
\text { بن يوسف، (ت: سبرهـ)، الناشر: مكتبة ابن تيمية. }
$$

• • ـ غيث النفع في القراعات السبع، المؤلف: علي بن محمد بن سالم، الصفاقسي (ت: 111111)، الناشر: دار الكتب العمية-بيروت، المحقق: أحمد محمود الحفيان، الطبعة: الأولى، هץ 1 هـ هـ ا Yـ الفاضل، المؤلف: محمد بن يزيد بن عبد الأكبر الثمالى الأزدي، أبو

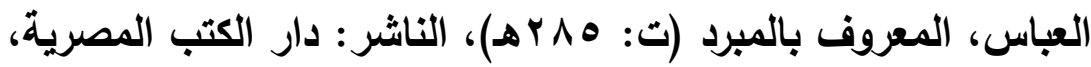

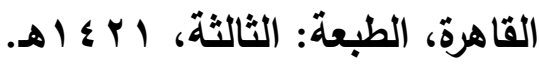
r r - فضائل القرآن، المؤلف: أبو عُبيد القاسم بن سلاّم الهروي (ت (ت 
צ צ r Pه)، المحقق: مروان العطية، ومحسن خرابة، ووفاء تقي الدين،

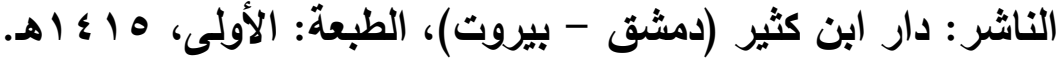
rr- فضائل القرآن، المؤلف : أبو الفداء إسماعيل بن عمر بن كثير القرشي البصري ثم الدمثقي (ت: \&VVه)، الناشر : مكتبة ابن

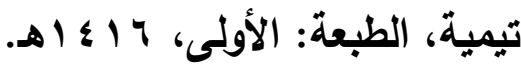

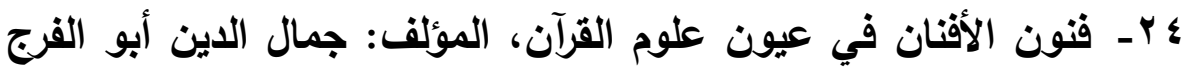

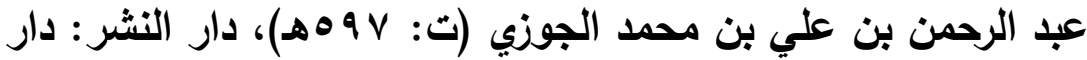

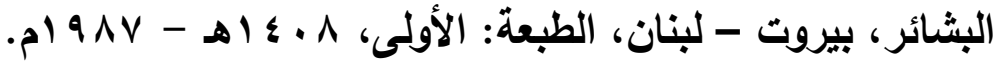
ه Y - الفهرست، المؤلف: محمد بن إسحاق بن محمد الولق، المعروف بابن

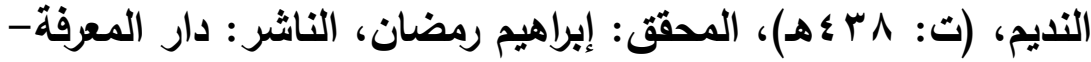

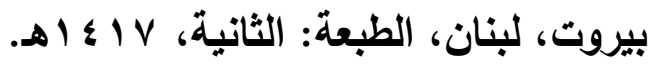
צr - في اللهجات العربية، المؤلف: إبراهيم أنيس، الناشر: مكتبة الأنجلو المصرية، الطبعة الثامنة، بو 99 ام. rV - في اللهجات العربية القديمة، المؤلف: إبراهيم السامرائي، الناشر : دار الحداثة للطباعة والنشر، بيروت، الطبعة الأولى، ؟ 99 ام. م.

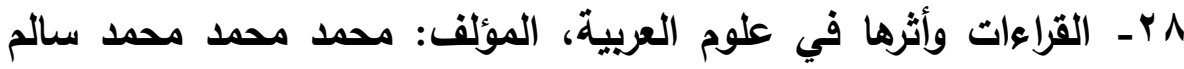

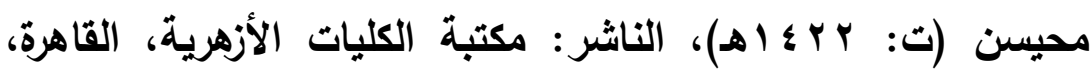

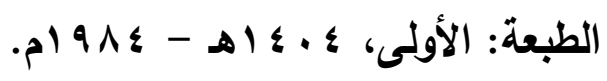

9 ؟- الكنز في القراءات العشر، المؤلف: أبو محمد، عبد الله بن عبد المؤمن بن الوجيه بن عبد الله بن على ابن المبارك التّاجر الواسطيّ

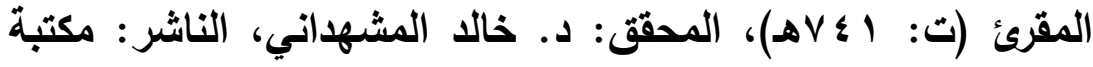


الثقافة الاينية، القاهرة، الطبعة: الأولى، هب ع اهـ - ع . . بم. • r- لسان العرب، المؤلف: محمد بن مكرم بن علي، ابن منظور الأنصاري

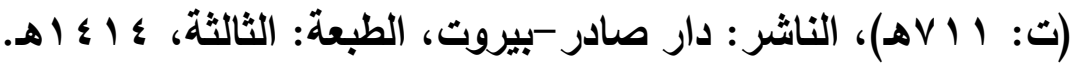
اب-ـ لهجة تميم وأثرها في العربية الموحدة، المؤلف: غالب فاضل المطلبي،

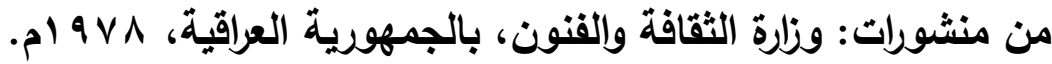
r r- اللهجات العربية في القراعات القرآنية، المؤلف: عبده الراجحي، الناشر: دار المعرفة الجامعية، الإسكندرية، 999 امئو 9 ام. rr- مجالس ثعلب، المؤلف: أحمد بن يحيى بن زيا بن سيار الشيباني بالولاء، أبو العباس، المعروف بثعلب (ت: ا و جهـ). ع ب- المحتسب في تبيين وجوه شواذ القراءات والإيضاح عنها، المؤلف: عثمان بن جني الموصلي (ت: rarهـ)، الناشر: وزارة الأوقافالمجلس الأعلى للشؤون الإسلامية، سنة: . ب ـ أهـ هـ - المخصص، المؤلف: علي بن إسماعيل بن سيده المرسي (ت) ^هـ هـ)، المحقق: خليل إبراهيم جفال، الناشر: دار إحياء التراث العربي-بيروت، الطبعة: الأولى، IV I أهـ דr-ـ المرشد الوجيز إلى علوم تتعلق بالكتاب العزيز، المؤلف: عبد الرحمن بن إسماعيل المقسي، المعروف بأبي شامة (ت: ه 7 هـ)، المحقق: طيار آلتي قولاج، الناشر: دار صادر -بيروت، سنة النشر: هو ه ا هـ. TV - المزهز في علوم اللغة وأنواعها، المؤلف: عبد الرحمن بن أبي بكر، جلال الاين السيوطي (ت: 119ه)، المحقق: فؤاد علي منصور، الناشر: دار الكتب العلمية - بيروت، الطبعة: الأولى، 1 أــأهـ - 
^r- مسند الإمام أحمد بن حنبل، المؤلف: أحمد بن محمد بن حنبل بن هلال الشيباني (ت: اءعه)، المحقق: شعيب الأرنؤوط، وعادل مرشد، وآخرن، إثراف: د عبد الله بن عبد المحسن التركي، الناشر: مؤسسة

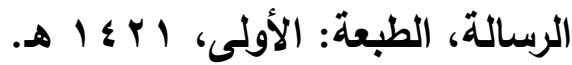
q ץ- المسند الصحيح المختصر بنقل العدل عن العدل إلى رسول الله ح، المؤلف: مسلم بن الحجاج القشيري النيسابوري (ت: آجrهـ)، المحقق: محمد فؤاد عبد الباقي، الناشر: دار إحياء التراث العربيبيروت. • ع - معاني القرآن، المؤلف: سعيد بن مسعدة المجاشعي بالولاء، المعروف .

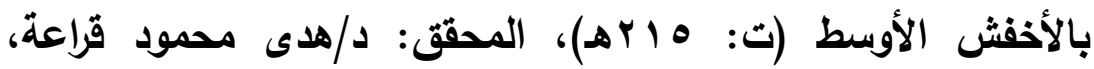
الناشر : مكتبة الخانجي، القاهرة، الطبعة: الأولى، 11 أهـ الهـ اءـ - معجم ما استعجم من أسماء البلاد والمواضع، المؤلف: أبو عبيد عبد الله بن عبد العزيز بن محمد البكري الأندلسي (ت: AV هـ)، الناشر: عالم الكتب، بيروت، الطبعة: الثالثة، ب م ــ اهـ. ץ צ- المعجم الوسيط، المؤلف: مجمع اللغة العربية بالقاهرة: إبراهيم مصطفى، وأحمد الزيات، وحامد عبد القادر، ومحمد النجار، الناشر: دار الدعوة.

بـ - مناهل العرقان في علوم القرآن، المؤلف: محمد عبد العظيم الزُّزقِقي (ت:

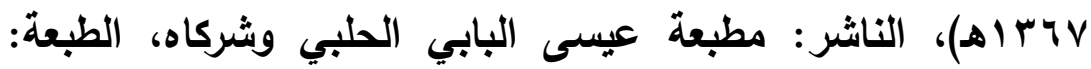
الطبعة الثالثة. 
؟ ـ - النشر في القراعات العثر، المؤلف : أبو الخير ابن الجزري، محمد بن محمد

بن يوسف (ت: سبر هـ) ، المحقق : علي محمد الضباع، (ت:

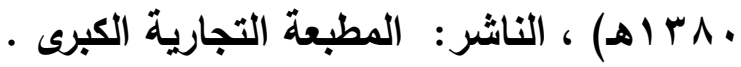

هـ ـ الهادي شرح طيبة النشر في القراءات العشر، المؤلف: محمد محمد محمد سالم محيسن (ت: r Y \& أه) ، الناشر: دار الجيل، بيروت،

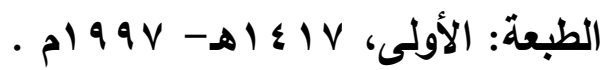

\ء - همع الهوامع في شرح جمع الجوامع، المؤلف: عبد الرحمن بن أبي بكر، جلال الدين السيوطي (ت: 119هـ ) ، المحقق: عبد الحميا

$$
\text { هنداوي، الناشر : المكتبة التوفيقية، مصر • }
$$

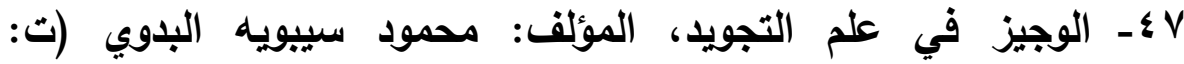
- (\$) 1 (10

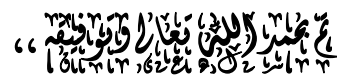

